\title{
Design of Near-Infrared-Absorbing Unsymmetrical Polymethine Dyes with Large Quadratic Hyperpolarizabilities
}

\author{
Simon Pascal, ${ }^{*,+,}$ Yulia A. Getmanenko, ${ }^{\ddagger}$ Yadong Zhang, ${ }^{\ddagger}$ Iryna Davydenko, ${ }^{\ddagger}$ Minh Hoang \\ Ngo, ${ }^{\S}$ Guillaume Pilet,, Sébastien Redon, ${ }^{\dagger}$ Yann Bretonnière, ${ }^{\dagger}$ Olivier Maury, ${ }^{\dagger}$ Isabelle \\ Ledoux-Rak, ${ }^{\S}$ Stephen Barlow, ${ }^{\ddagger}$ Seth R. Marder ${ }^{\star, \ddagger}$ and Chantal Andraud ${ }^{*, \dagger}$
}

†Univ. Lyon, ENS de Lyon, CNRS UMR 5182, Université Claude Bernard Lyon 1, Laboratoire de Chimie, F69342, Lyon, France.

${ }^{\star}$ School of Chemistry and Biochemistry and Center for Organic Photonics and Electronics, Georgia Institute of Technology, Atlanta, GA 30332-0400, USA.

$\S$ ENS Paris Saclay, CNRS UMR 8537, 61 avenue du Président Wilson, 94235 Cachan Cedex, France.

"Laboratoire des Multimatériaux et Interfaces, CNRS UMR 5615, Université Claude Bernard Lyon 1, Campus de La Doua, 69622 Villeurbanne Cedex, France.

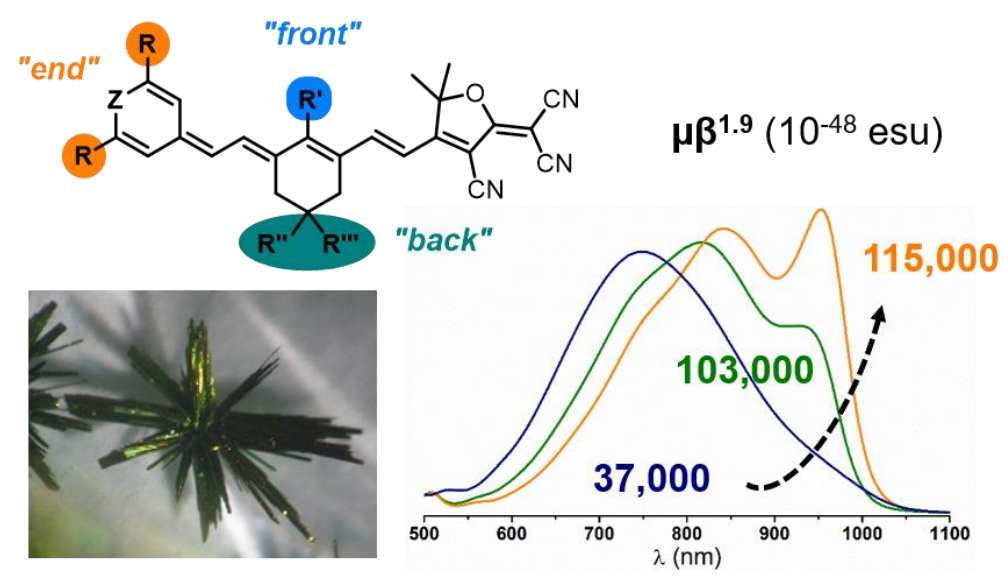

\section{ABSTRACT}

Abstract: Fifteen heptamethine dyes in which a tricyanofuran acceptor is linked to donors of different strength were synthesized, and their absorption, thermal, electrochemical, and second-order nonlinear optical properties were investigated. While the variation of the peripheral bulky substituents allowed a decrease of the intermolecular interactions in the solid state, subtle engineering of the heterocyclic donor provided dyes with electronic structures that varied between dipolar and cyanine-like (i.e. with little bond length alternation and with ground and excited states having similar dipole moment) and remarkably high quadratic hyperpolarizabilities $\left(\mu \beta^{1.9}\right)$ of up to $115,000 \times 10^{-48} \mathrm{esu}$. 


\section{INTRODUCTION}

Organic second-order nonlinear optical (NLO) chromophores have been widely investigated for electro-optical (EO) applications; ; ${ }^{1-3}$ EO modulators based upon organic molecules can be modulated at very high frequency giving extraordinary bandwidths. The flexibility of organic synthesis enables the incorporation of subtle structure modifications and, therefore, the ability to tune the electronic structure so as to optimize the NLO response at the microscopic level and, to some extent, control chromophore-chromophore interactions in the solid state. The main factors that facilitate the design, synthesis, and processing of efficient materials for EO modulation are: (i) high quadratic hyperpolarizability $\beta$, (ii) good thermal and chemical stability, (iii) possible large scale synthesis of the dye, and (iv) adequate solubility for further incorporation into devices.

Among the numerous organic molecules developed for the second order NLO applications, "push-pull" chromophores have been extensively investigated, ${ }^{4}$ including those using the strong tricyanofuran (TCF) acceptor, which also enables dyes with good solublity to be obtained. Well-known examples of molecules bearing TCF are CLD-1 and FTC (Table 1), which possess the required characteristics for EO applications, e.g. high second-order NLO response at a wavelength of $1.9 \mu \mathrm{m}$, $\mu \beta^{1.9}$ ( $\mu$ being the permanent dipole moment of the molecule and $\beta$ the second-order molecular polarizability), of around $20,000 \times 10^{-48} \mathrm{esu}$, good solubility in the solvents used for the fabrication of EO devices, and suitable thermal stability. ${ }^{5-7}$ Importantly, the structure of CLD-1 has been optimized using TCF-CF3 moieties which led to large $\beta^{1.9}$ values of 7,600 $\times 10^{-}$ ${ }^{30}$ esu and remarkable EO properties following chemical engineering with bulky substituents. ${ }^{8-10}$

The TMC-3 dye (Table 1), featuring a strong intramolecular charge transfer is one of the most promising chromophores for EO applications. ${ }^{11-13}$ Its giant $\mu \beta$ value, up to $-488,000 \times 10^{-48}$ esu is a consequence of a ground state zwitterionic electronic structure, resulting in a very large dipole moment. A major challenge for using highly dipolar chromophores in poled polymers, however, is aggregation, which can occur at high chromophore concentrations. Typically, this aggregation leads to the formation of centrosymmetric dimers or multichromophore aggregates, and consequentially a dramatic decrease of the nonlinear response.

Table 1. Structures and second-order nonlinearities of the known CLD-1, FTC, ${ }^{5-7}$ TMC-3 ${ }^{11-13}$ and CPO-1 ${ }^{14-16}$ dipolar chromophores and of the new dye S2a described in this study. $\mu \beta^{1.9}$ values are measured using the EFISH technique, $\beta^{1.9}$ values are measured by HRS at $1907 \mathrm{~nm}$.

(n)


Recently, the gram-scale preparation of the unsymmetrical CPO-1 polymethine and an evaluation of its NLO properties were reported (Table 1). ${ }^{14-16}$ This dye is readily obtained following five synthetic steps with a ca. $79 \%$ overall yield and exhibits good thermal stability, high quadratic hyperpolarizability $\left(\mu \beta^{1.9}\right)$ and promising EO response.

Given the promising characteristics of CPO-1, the present study is focused on systematic modification of its chemical structure in order to further increase the thermal stability and the quadratic hyperpolarizability of the chromophore. Inspired by recent work on near-infrared (NIR) symmetrical cationic polymethines, ${ }^{17-18}$ fifteen new unsymmetrical heptamethines incorporating a TCF acceptor and chalcogenopyran or benzoindoline donors were prepared (Figure 1) to investigate effect on optical and electronic properties. To reduce detrimental chromophore-chromophore interactions in the solid state incorporation of the "front" and "back" groups using moderate to large steric bulkiness was examined.

A wide range of pyran, thiopyran, selenopyran, benzoindoline or indoline derivatives investigated by UV-visNIR absorption spectroscopy and cyclic voltammetry demonstrates the strong influence of the donor fragments on their optical and electronic properties. Absorption solvatochromism experiments indicates a progressive establishment of a highly delocalized cyanine-like electronic structure in polar solvents. This observation is quite significant since the polyene-like and cyanine-like polymethines respectively display positive and null bond length alternation (BLA), a parameter directly related to the second order hyperpolarizability. ${ }^{19-22}$ High quadratic hyperpolarizabilities $\mu \beta^{1.9}$ are recorded in solution for the present scope of polymethines, as illustrated by $\mathbf{S 2 a}$ in Table 1 .

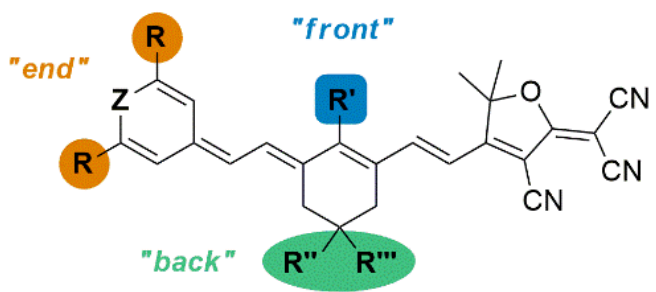

\begin{tabular}{|c|c|c|c|c|c|}
\hline \multirow[t]{2}{*}{ Compound } & \multirow{2}{*}{$\begin{array}{c}\text { Chalcogen } \\
\text { Z }\end{array}$} & \multirow{2}{*}{$\begin{array}{c}\text { "End" } \\
\text { R }\end{array}$} & \multirow{2}{*}{$\begin{array}{c}\text { "Front" } \\
\mathrm{R}^{\prime}\end{array}$} & \multicolumn{2}{|c|}{ "Back" } \\
\hline & & & & $\mathrm{R}^{\prime \prime}$ & $\mathrm{R}^{\prime \prime \prime}$ \\
\hline $01 a$ & 0 & ${ }^{t} \mathrm{Bu}$ & $\mathrm{Cl}$ & ${ }^{t} \mathrm{Bu}$ & $H$ \\
\hline 02a & O & $\mathrm{Ad}$ & $\mathrm{Cl}$ & ${ }^{t} \mathrm{Bu}$ & $\mathrm{H}$ \\
\hline s1a & $S$ & ${ }^{t} \mathrm{Bu}$ & $\mathrm{Cl}$ & ${ }^{t} \mathrm{Bu}$ & $H$ \\
\hline s1b & $S$ & ${ }^{t} \mathrm{Bu}$ & $\mathrm{cbz}$ & $\mathrm{H}$ & $\mathrm{H}$ \\
\hline s1c & $S$ & ${ }^{t} \mathrm{Bu}$ & $\mathrm{Cl}$ & & \\
\hline s2a & $s$ & $\mathrm{Ad}$ & $\mathrm{Cl}$ & ${ }^{t} \mathrm{Bu}$ & $\mathrm{H}$ \\
\hline$S 2 b$ & $S$ & $\mathrm{Ad}$ & $\mathrm{cbz}$ & $\mathrm{H}$ & $\mathrm{H}$ \\
\hline s3a & $S$ & $\mathrm{Ph}$ & $\mathrm{Cl}$ & ${ }^{t} \mathrm{Bu}$ & $\mathrm{H}$ \\
\hline Se1a & $\mathrm{Se}$ & ${ }^{t} \mathrm{Bu}$ & $\mathrm{Cl}$ & ${ }^{t} \mathrm{Bu}$ & $\mathrm{H}$ \\
\hline Se1b & $\mathrm{Se}$ & ${ }^{t} \mathrm{Bu}$ & $\mathrm{cbz}$ & $\mathrm{H}$ & $\mathrm{H}$ \\
\hline Se2a & $\mathrm{Se}$ & $\mathrm{Ad}$ & $\mathrm{Cl}$ & ${ }^{t} B u$ & $\mathrm{H}$ \\
\hline $\mathrm{Se} 2 \mathrm{~b}$ & $\mathrm{Se}$ & $\mathrm{Ad}$ & $\mathrm{cbz}$ & $\mathrm{H}$ & $\mathrm{H}$ \\
\hline
\end{tabular}

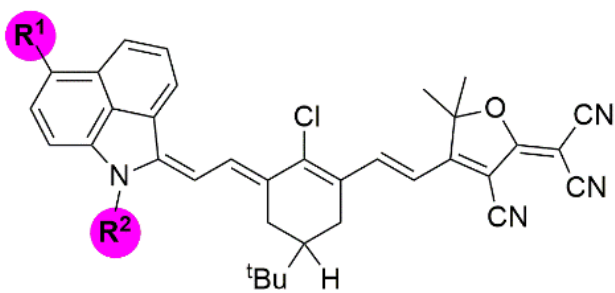

N1a: $R^{1}=\mathrm{H} ; \mathrm{R}^{2}=\mathrm{C}_{4} \mathrm{H}_{9}$ N2a: $R^{1}=d m p ; R^{2}=C_{12} \mathrm{H}_{25}$
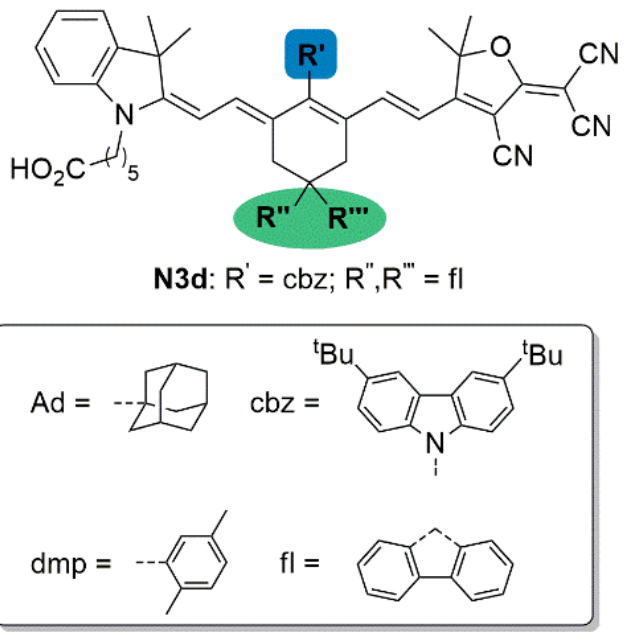

Figure 1. Structures of unsymmetrical polymethine dyes studied here. 


\section{RESULTS AND DISCUSSION}

Synthesis. The target dyes were obtained by two consecutive condensations, as depicted in Scheme $1 .^{14,16}$ First, the "bisaldehyde-like" precursors 1a-d with different "front"/"end" groups combinations ((a): $\mathrm{Cl} /{ }^{\prime}$ butyl, $\mathrm{H} ;(\mathbf{b})$ : cbz/H,H; $(\mathbf{c}): \mathrm{Cl} / \mathrm{fl}$; and (d) cbz/fl) were reacted with a TCF derivative to give corresponding adducts $\mathbf{2}$ in moderate to good yields. With these four intermediates 2a-d in hand, formation of the unsymmetrical polymethines was accomplished by a second high-yield condensation with pyrylium, thiopyrylium, selenopyrylium, benzoindolenium or indolenium salts. The final dyes depicted in Figure 1 incorporate chalcogenopyran moieties with 'butyl (dyes O1, S1, Se1), adamantyl (dyes O2, $\mathbf{S 2}$, Se2) or phenyl (dye S3) "end" groups and benzoindoline donors with a butyl chain (dye N1) or a long dodecyl chain with additional 2,5-dimethylphenyl substituent (dye N2). Polymethine N3d, an analogue of CPO-1 with di- ${ }^{t} \mathrm{Bu}-$ carbazole $^{-}$ "front" and fluorene "back" substituents, was prepared in order to examine the changes in the thermal stability brought about by bulky groups. The new compounds were characterized by high-resolution mass spectrometry (HRMS), and NMR spectroscopy (spectra provided in the ESI). All final chromophores exhibit a metallic green luster in the solid state, characteristic of several strongly absorbing far-red to NIR polymethine dyes. The ${ }^{1} \mathrm{H}$ NMR spectra are consistent with alltrans configurations for the polymethine bridge, but with BLA reduced from that seen in simple polyenes $\left({ }^{3} \mathrm{~J}=12-13 \mathrm{~Hz}\right)$.

Scheme 1. General synthesis of the new unsymmetrical polymethine dyes with chalcogenopyran, benzoindoline and indoline donor groups.
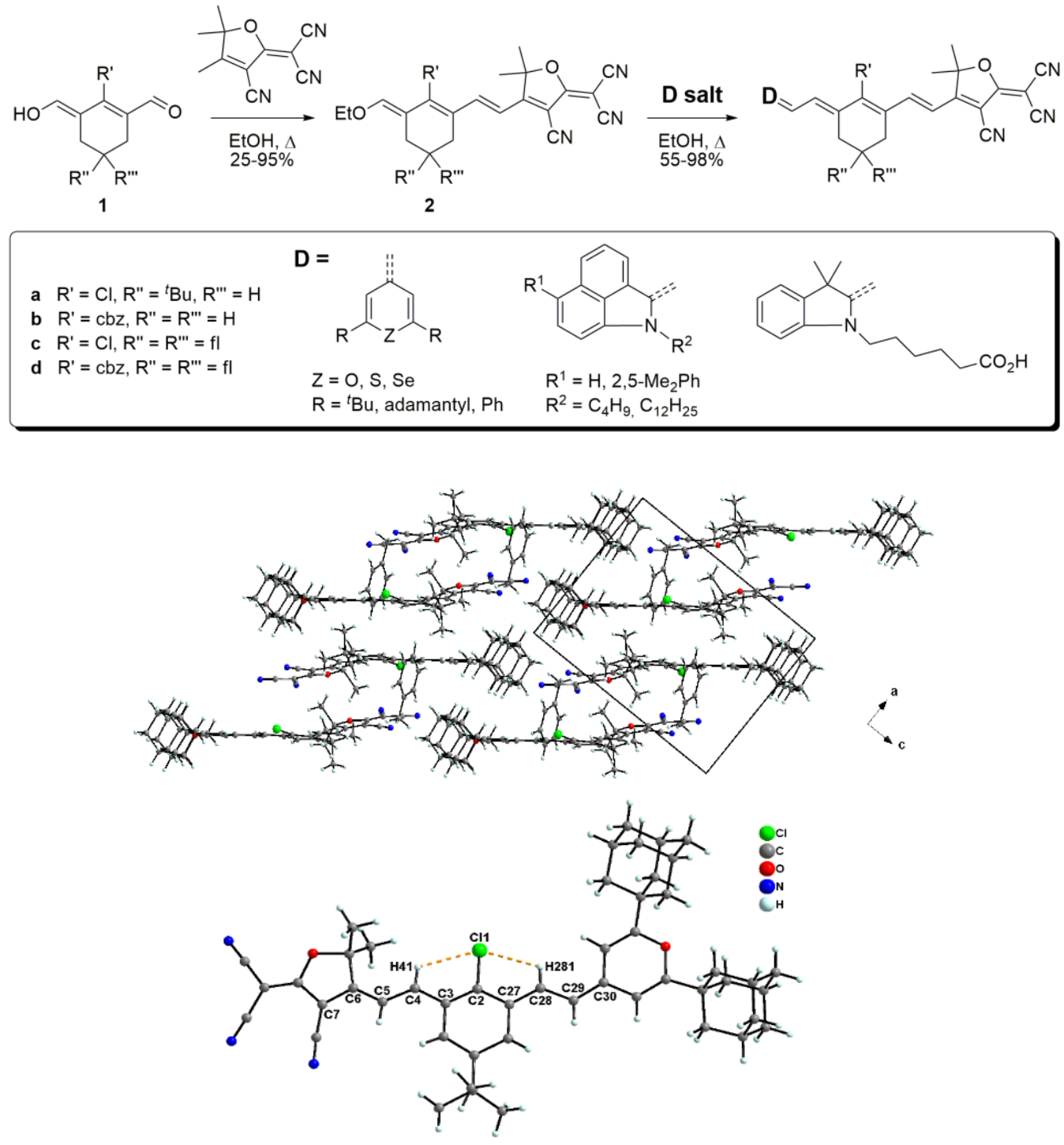

Figure 2. Left: crystal packing of O2a •toluene in columns running along the a-axis of the unit-cell. Right: Crystal structure of O2a with labeled polymethine bridge atoms. Orange dashed lines represent hydrogen bonds. A co-crystallized toluene solvent molecule has been omitted for clarity. 
X-ray crystallography. An X-ray quality crystal of compound O2a was obtained by slow evaporation of a toluene solution over 2 weeks. The X-ray data were collected immediately to avoid any solvent loss from the crystal (see ESI for details on the data collection and the refinement results). The final refined formula is [O2a $\cdot$ (toluene)] where one molecule of toluene co-crystallizes with one O2a molecule in the unit-cell. The crystal packing can be viewed as columns of O2a molecules running along the $a$-axis of the unit-cell (Figure 2, left). Within the column, molecules stack in a head to tail mode and the average plane-to-plane distance between two neighboring molecules is equal to 3.93(1) $\AA$. Toluene cocrystallized solvent molecules are inserted between dye molecules and columns. The whole crystal packing is then ensured by weak interactions.

Table 2. Important bond lengths within crystal structure of O2a.

\begin{tabular}{cccc} 
Bond & $\begin{array}{c}\text { Bond length / } \\
\AA\end{array}$ & Bond & $\begin{array}{c}\text { Bond length / } \\
\AA\end{array}$ \\
C6-C5 & $1.398(6)$ & C5-C4 & $1.374(6)$ \\
C4-C3 & $1.411(6)$ & C3-C2 & $1.372(6)$ \\
C2-C27 & $1.430(5)$ & C27-C28 & $1.383(6)$ \\
C28-C29 & $1.401(5)$ & C29-C30 & $1.380(5)$ \\
\hline
\end{tabular}

The crystallographically determined molecular structure (Figure 2, right) revealed a trans configuration of the polymethine bridge without any large twist of the $14 \mathrm{sp}^{2}$ carbonskeleton. The geometry of the molecule is influenced by

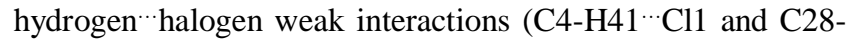
$\mathrm{H} 281 \cdots \mathrm{Cl} 1,2.41(1)$ and 2.51(5) ̊̊ respectively). The conjugated $\mathrm{C}_{6}-\mathrm{C}_{30}$ carbon chain is constituted of alternating long (average bond length: 1.410(6) $\AA$ ) and short (average bond length: 1.377(8) $\AA$ ) $\mathrm{C}\left(\mathrm{sp}^{2}\right)-\mathrm{C}\left(\mathrm{sp}^{2}\right)$ bonds, with a BLA value of 0.03(3) $\AA$ within the central heptamethine bridge (see Table 2). This value is lower than that seen in the crystal structure of polymethine CPO-1 (BLA $=0.06 \AA),{ }^{14}$ indicating an increased contribution from the zwitterionic resonance structure for O1a, resulting in a somewhat more cyanine-like structure (vide infra), at least in its crystals. ${ }^{23}$

Thermogravimetric analysis. The thermal stability of the dyes was evaluated by thermogravimetric analysis under inert atmosphere, and the decomposition temperatures corresponding to a $10 \%$ weight loss $\left(\mathrm{T}_{\mathrm{d} 10}\right)$ are summarized in Table 3 . All dyes possess good to excellent thermal stability with decomposition temperatures between $255^{\circ} \mathrm{C}$ for Se2a and $370{ }^{\circ} \mathrm{C}$ for Se2b. It is important to note that the introduction of a di- ${ }^{\mathrm{B}} \mathrm{Bu}$-carbazole "front" functional group in place of chlorine significantly improves thermal stability, especially in the case of the N3d dye, for which $\mathrm{T}_{\mathrm{d} 10}$ is increased by $50{ }^{\circ} \mathrm{C}$ in comparison to its chloro-substituted analogue CPO-1.

Absorption spectroscopy. The UV-vis-NIR absorption properties of the fifteen dyes were recorded at room temperature in dichloromethane solution (ca. $10^{-5} \mathrm{M}$ ) and the data are summarized in the Table 3 . The absorption spectra presented in Figure 3 show the dependence of these spectra on the nature of chalcogen in the chalcogenopyran dyes (Figure 3, A/ and D/), of the "end" moieties of thiopyran dyes (Figure 3, B/), of the "front" or "back" substituents of chalcogenopyrans (Figure 3, $\mathrm{C} /$ and $\mathrm{E} /$ ), and of the various structural features of the (benzo)indoline-based derivatives (Figure 3, F/).

All these unsymmetrical polymethines display relatively broad and strong absorption bands centered in the red to NIR spectral range $(600-1000 \mathrm{~nm})$, molar extinction coefficients $(\varepsilon)$ ranging from 60,000 (Se1a) to $100,000 \mathrm{M}^{-1} \mathrm{~cm}^{-1}$ (N3d), and full widths at half-maximum (FWHMs) ranging from 2,200 (N3d) to $4,300 \mathrm{~cm}^{-1}$ (S2a). In most cases, absorption spectra consist of a relatively broad high-energy component, in some cases with poorly resolved, presumably vibronic, structure, and a lower energy relatively narrow feature, which varies from the most
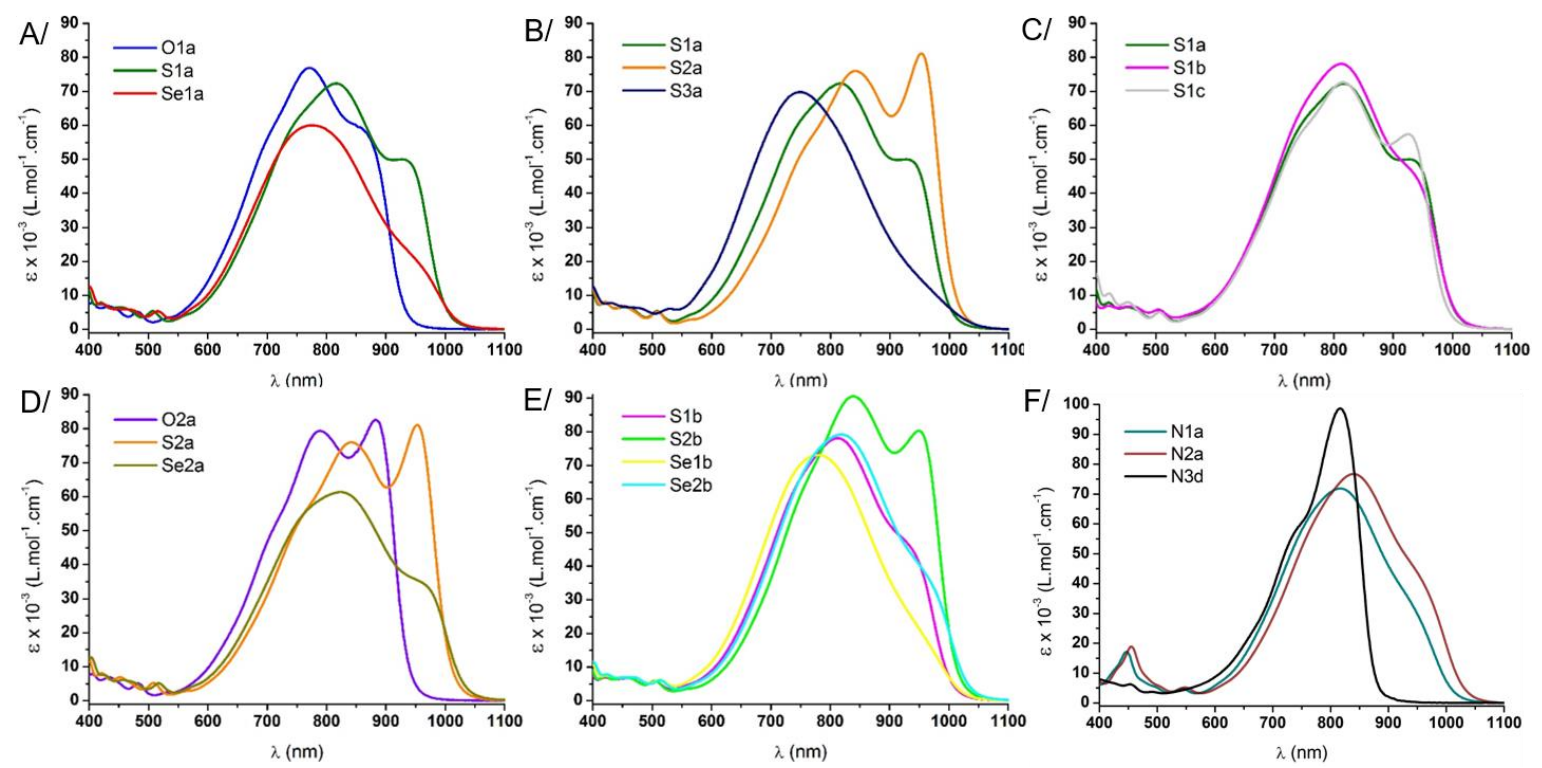

Figure 3. Comparative absorption spectra, in dichloromethane solutions ( $\left.\mathrm{ca} .10^{-5} \mathrm{M}\right)$, of the polymethines studied in this work. 
strongly absorbing feature in the spectrum for some compounds (e.g., S2a) to a barely discernible shoulder for others (S3a). The absorption spectra of the O-, S-, Se-pyrylium-terminated polymethines (Figure 3, A/ and D/) reveal a $40 \mathrm{~nm}$ (ca. 700 $\mathrm{cm}^{-1}$ ) red-shift of the most prominent transition for dye $\mathbf{S 1 a}$ compared to O1a and Se1a. A similar trend is observed for $\mathbf{S 2 a}$ compared to $\mathbf{0 2 a}$ and Se2a. The influence of the "end" substituents is evaluated for the thiopyran derivatives S1-3a (Figure 3, B/). The phenyl-containing polymethine S3a exhibits the most blue-shifted absorption band, featuring a particularly structureless profile. The absorption of tbutyl and adamantylcontaining dyes S1a and $\mathbf{S 2 a}$ are red-shifted and show a more well-defined sharp low-energy feature, which is centered at 950 nm. Such a comparison suggests that the lower energy band intensity is correlated with the increasing electron-rich character of the thiopyran extremity, as indicated by cyclic voltammetry (vide infra). The possible origin of the broad and sharp features is discussed below in the context of the solvatochromism of these compounds.

Not surprisingly, the "front" and "back" substituents in the S1a-c series (Figure 3, see $\mathrm{C} /$ and $\mathrm{E} /$ ) have relatively little influence on the absorption bands. Corresponding absorption profiles are almost superimposable, with largest differences in the low energy transition. Benzoindoline-containing polymethines N1a and N2a display comparable almost structureless absorption bands (Figure 3, F/). The noticeable absorption red-shift compared to that of the N3d indolinecontaining dye is explained by the conjugation extension brought by the additional benzene ring in N1a and N2a. Polymethine N3d exhibits the most pronounced contribution of the low energy band within the whole series.

Table 3. Linear optical and thermal data for polymethines.

\begin{tabular}{cccc} 
Compound & $\begin{array}{c}\lambda_{\max } / \mathrm{nm}_{\left(\varepsilon_{\max } \times 10^{-3} /\right.} \\
\left.\mathbf{M}^{-1} \mathrm{~cm}^{-1}\right)^{[\mathrm{a}]}\end{array}$ & $\begin{array}{c}\lambda_{\mathrm{em}} / \mathrm{nm} \\
{[\mathrm{a}]}\end{array}$ & $\begin{array}{c}\mathrm{T}_{\mathrm{d} 10} / \\
{ }^{\circ} \mathrm{C}^{[\mathrm{b}]}\end{array}$ \\
O1a & $771(77)$ & 931 & 280 \\
O2a & $789(79), 882(82)$ & 932 & 270 \\
S1a & $816(72)$ & 986 & 285 \\
S1b & $812(78)$ & 988 & 325 \\
S1c & $816(73)$ & 974 & 275 \\
S2a & $842(76), 953(81)$ & 993 & 305 \\
S2b & $839(91), 949(80)$ & $n . d$. & $n . d$. \\
S3a & $748(69)$ & 1068 & 300 \\
Se1a & $775(60)$ & 1008 & 300 \\
Se1b & $779(73)$ & 1012 & 340 \\
Se2a & $824(61)$ & 1016 & 255 \\
Se2b & $819(80)$ & 1017 & 370 \\
N1a & $817(72)$ & 1008 & 260 \\
N2a & $840(77)$ & 1022 & 285 \\
N3d & $816(100)$ & 862 & 300 \\
\hline
\end{tabular}

[a] In dichloromethane. [b] Decomposition temperature with $10 \%$ weight loss measured by TGA.
This particularly sharp $\left(\mathrm{FWHM} \sim 2,000 \mathrm{~cm}^{-1}\right)$ and strong $(\varepsilon=$ $100,000 \mathrm{M}^{-1} \mathrm{~cm}^{-1}$ ) absorption is accompanied by a high energy shoulder, possibly vibronic in origin, and is reminiscent of the transitions commonly observed for symmetrical cyanines and cyanine-like polymethines (vide infra). ${ }^{24}$

Absorption solvatochromism. According to previous studies $^{25-35}$ the balance of the electron-donating/withdrawing strengths at the extremities of a push-pull polymethine can modulate the low-energy band between relatively broad chargetransfer-like band shapes and a very sharp feature with much higher peak absorptivity. A narrow band shape indicates that polymethine has a cyanine-like electronic structure, characterized by a near-zero BLA (Figure 4), which can be thought of as arising from equal contributions of neutral and zwitterionic resonance structures. Unsymmetrical polymethines are known to be sensitive to their environment: a polar solvent will favor more strongly dipolar structures and so can drive a structure from polyene-like to cyanine-like, or from cyaninelike to zwitterionic. ${ }^{16,36}$
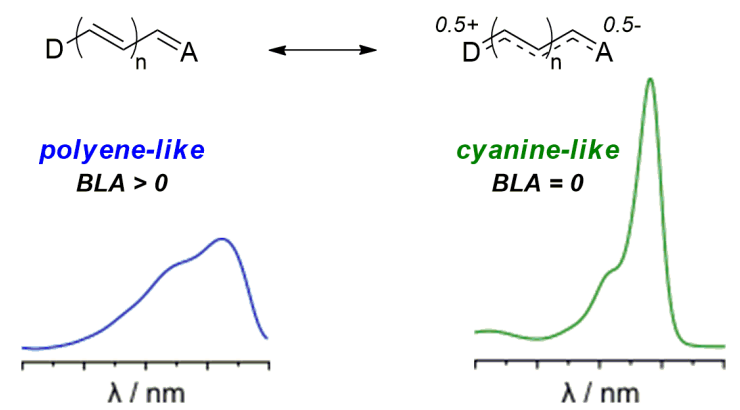

Figure 4. Representation of the polyene-like and cyanine-like electronic structures of polymethine dyes and of their corresponding absorption profiles.
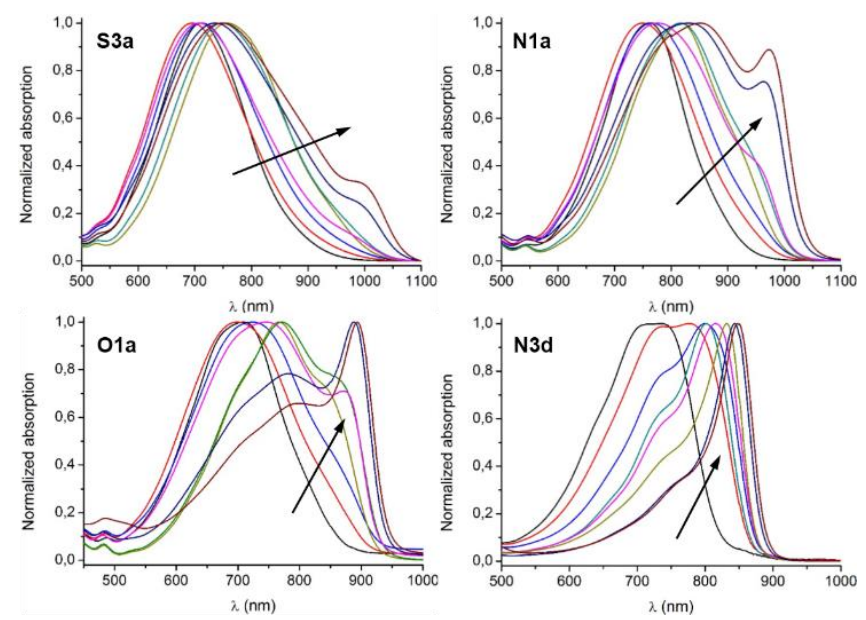

Figure 5. Absorption solvatochromism for polymethines S3a, N1a, O1a and N3d in toluene (black), ethyl acetate (red), tetrahydrofuran (blue), chloroform (dark yellow), dichloromethane (cyan), acetone (magenta), N,N-dimethylformamide (navy), dimethylsulfoxide (wine).

The behavior of the present series of polymethines was further investigated by studying the absorption solvatochromism of selected compounds in a wide range of 
medium polarity. Most of the molecules feature a broad nearGaussian band in less polar solvents (Figures 5 and S67). The solvatochromism of polymethine $\mathbf{N 3 d}$ is perhaps the most straightforward, and is similar to that of its CPO-1 analogue. ${ }^{16}$ The spectrum is red-shifted and increasingly cyanine-like as the solvent polarity is increased, consistent with expectations of a more polar solvent on the BLA. In contrast, the spectra of S3a and N1a display a progressive red-shift of the absorption maxima with increasing polarity and reveal the appearance of a relatively sharp low-energy peak at $950 \mathrm{~nm}$ in the most polar solvents (DMF and DMSO). In the case of O1a, the solvent polarity has a more dramatic influence on the shape of the absorption bands. The growing feature centered at $900 \mathrm{~nm}$ becomes stronger than the broad band with $\lambda_{\max }$ at around 750 $\mathrm{nm}$ and is weakly shifted upon increasing polarity. Such a behavior is more pronounced than that seen in other donoracceptor polyenes in that, in the more polar solvents, apparently cyanine-like and polyene-like features are simultaneously present. These spectra (including many of the $\mathrm{CH} 2 \mathrm{Cl} 2$ spectra shown in Figure 3) are reminiscent of what is seen for certain long-chain nominally symmetrical cyanine-like ionic polymethines. ${ }^{37,23,38-42}$ The origin of such spectra are not
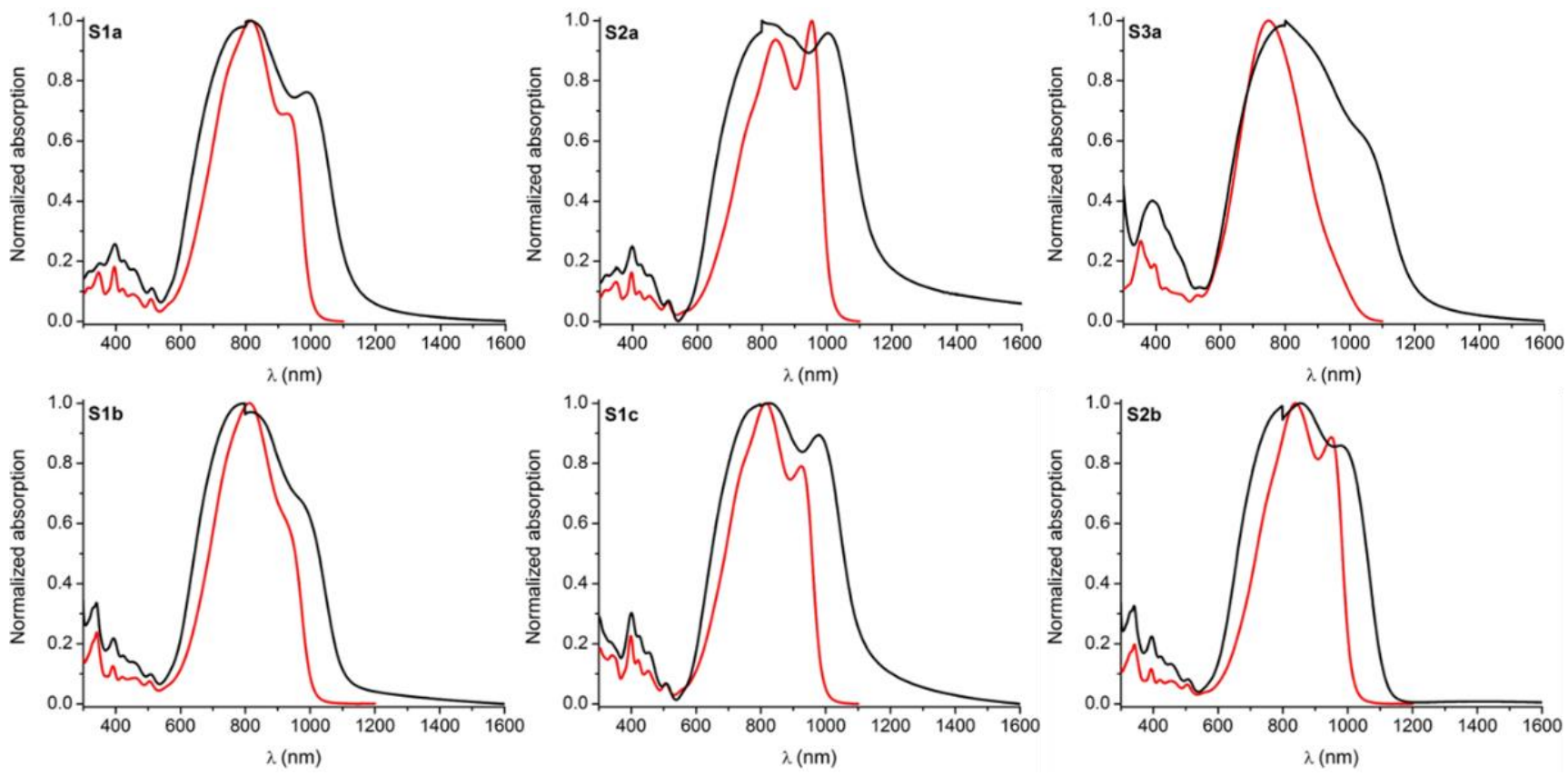

Figure 6. Normalized absorption spectra in dichloromethane solutions (red, ca. 10-5 M) and films of 100 wt $\%$ dye (black). 
a noticeable shift of the onset of absorption and/or scattering to beyond $1600 \mathrm{~nm}$. Polymethine S3a reveals the most pronounced broadening of absorption towards low energy. The spectrum suggests the formation of a new aggregate transition, the terminal phenyl groups being inefficient at preventing intermolecular interactions in the solid state (consistent with what is seen in bis(chalcogenopyrylium)-terminated heptamethines ${ }^{18}$ ). Introduction of the fluorenyl moiety in the "back" position (S1c) provides no significant change of absorption profile compared to S2a, whereas the di- ${ }^{t} \mathrm{Bu}$-carbazole substituent in $\mathbf{S 1 b}$ affords the smallest shifts in the red absorption edge. The combination of bulky adamantyl "end" and di- ${ }^{t}$ Bu-carbazole "back" groups (S2b) leads to the spectra that show the least difference between the solution and solid states, the solid-state spectra exhibiting a welldefined low-energy cut-off at $1150 \mathrm{~nm}$. These results demonstrate that the combination of selected bulky substituents provides a control of the absorption properties in the solid state, as recently observed for Pd-substituted polymethines. ${ }^{46}$ However, the quasisuppression of aggregation evidenced here does not prevent an antiparallel alignment (hence centrosymmetric) of neighboring dipolar molecules, as found in the crystal structure of O1a.

Cyclic voltammetry. To gain insight into the relative strength of the various electron-donating extremities, the redox properties of selected compounds were investigated by cyclic voltammetry in dichloromethane (Table 4). The $\pi$-donor strength of the chalcogenopyran moieties can be compared by examining the reduction potentials of polymethines O1a, S1a and Se1a. The compounds become increasingly easier to reduce from $\mathrm{O}$ - to $\mathrm{S}$ - to Se-containing dyes $(-1.03,-0.99,-0.95 \mathrm{~V}$ respectively). This suggests that the $\pi$-donor strength decreases in the order pyran > thiopyran > selenopyran, leading to a decreased contribution from the zwitterionic resonance structure and to moving the electronic structure of the dyes away from the cyanine limit (consistent with the relative importance of the sharp low-energy transition in absorption spectra seen in Figure 3, A/). ${ }^{47}$

Table 4. Redox potentials vs. $\mathrm{FeCp}_{2}{ }^{+/ 0}$ in dichloromethane / 0.1

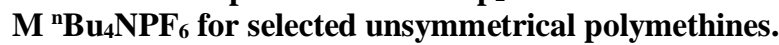

\begin{tabular}{ccc} 
Compound & $\mathrm{E}_{1 / 2}+/ 0 / \mathrm{V}$ & $\mathrm{E}_{1 / 2}{ }^{0 /-} / \mathrm{V}$ \\
O1a & +0.14 & -1.03 \\
S1a & +0.06 & -0.99 \\
Se1a & +0.15 & -0.95 \\
S2a & +0.06 & -1.00 \\
S3a & +0.17 & -0.92 \\
N1a & +0.18 & -0.96 \\
\hline
\end{tabular}

As expected, the adamantyl-substituted compound (S2a) has redox potentials similar to its tbutyl analogue (S1a). The phenylbased thiopyran (S3a) appears to be a slightly weaker donor than its alkyl analogues with reduction occurring at $-0.92 \mathrm{~V}$. The phenyl groups presumably act themselves as mild $\pi$-acceptors, thereby decreasing the donor's electron-density. This observation correlates with the absorption shift observed in Figure $3(\mathrm{~B} /)$, where the alkyl end groups induce a red-shift of the absorption maxima. The polymethine N1a shows similar reduction potential to Se1a, which is consistent with the comparable structure of their absorption spectra.

Fluorescence spectroscopy. Luminescence measurements in dichloromethane solution (Table 3 and Figure S68) show that these polymethines display detectable fluorescence in the NIR with lifetimes $<0.4 \mathrm{~ns}$. The emission bands are characterized by a sharp profile (FWHM generally $\sim 1500-2000 \mathrm{~cm}^{-1}$ ), especially in the case of the N3d dye (FWHM $\sim 700 \mathrm{~cm}^{-1}$ ). It is worth noting that N3d presents the smallest Stokes shift, consistent with its more cyanine-like absorption spectrum (Figure S69).

Second-order nonlinear optical properties. The quadratic hyperpolarizabilities of the new chromophores were determined by Electric Field Induced Second Harmonic (EFISH) ${ }^{48-49}$ and Hyper Rayleigh Scattering (HRS) ${ }^{50-51}$ measurements at $1907 \mathrm{~nm}$ in chloroform solution, and results are summarized in Table 5. Due to the high absorption of our molecules at the second harmonic wavelength at $955 \mathrm{~nm}, \mu \beta^{1.9}$ values were inferred from experimental second-harmonic intensity values corrected according to the Beer-Lambert law of solution absorption using a $10^{\text {slc }}$ factor where $\varepsilon$ is the molar extinction coefficient of the sample at $955 \mathrm{~nm}, 1$ the thickness of the solution, and $\mathrm{c}$ its concentration. Measurements were carried out at low concentrations not exceeding $10^{-4} \mathrm{M}$ in order to minimize this correction factor $\left(10^{\text {slc }}<3\right)$.

With that said, high to exceptionally high quadratic hyperpolarizabilities were recorded by EFISH for all these polymethines. Compounds O1a and O2a with the pyran donor show large $\mu \beta^{1.9}$ values of $26,000 \times 10^{-48}$ esu and $36,600 \times 10^{-48} \mathrm{esu}$, respectively. The thio- and selenopyran-containing derivatives display higher $\mu \beta^{1.9}$ values between $86,300 \times 10^{-48}$ esu (S1b) and $115,000 \times 10^{-48}$ esu $(\mathbf{S 2 a})$, with the exception of dye $\mathbf{S 3 a}$ with $\mathrm{Ph}$ "end" groups, which displays a $\mu \beta^{1.9}$ of $37,000 \times 10^{-48}$ esu. Dyes N1a and N2a with benzoindoline donor display hyperpolarizabilities of the order of $100,000 \times 10^{-48} \mathrm{esu}$, whereas N3d response is more modest, with $28,000 \times 10^{-48}$ esu. This latter value is consistent with the one obtained for CPO-1 with similar conjugated backbone, ${ }^{16}$ and with their more cyanine-like absorption spectra. The influence of the "front" and "back" substituents is weak, with $\mu \beta^{1.9}$ in the range of 90,000$100,000 \times 10^{-48}$ esu for the S1a-c series, in agreement with the tendency observed for linear absorption (Figure 3, C/).

Interestingly, polymethines O1a, O2a, S3a and N3a have the smallest nonlinear responses in the series, which can be correlated to their low absorption intensity at $955 \mathrm{~nm}$ corresponding to a weaker resonance with the incident light harmonic. Dyes Se1a and Se1b have similar quadratic hyperpolarizabilities, with $53,000 \times 10^{48}$ esu and $67,000 \times 10^{48}$ esu respectively. The quadratic hyperpolarizabilities were also evaluated by HRS and show reasonable values ranging from about $2,600 \times 10^{-30}$ (S1b) to $6,500 \times 10^{-30}$ esu $(\mathbf{S e 2 b})$. These results are among the highest responses measured for organic dyes. It must be pointed-out that HRS results do not necessarily follow the trends observed for $\mu \beta$ values inferred by EFISH, as $\beta_{\mathrm{HRS}}$ values contain, not only the 
dipolar contribution to the $\beta$ values, but also potentially nonnegligible octupolar contribution that are not correlated to its dipolar counterpart. ${ }^{52}$

Table 5. Quadratic hyperpolarizabilities of polymethines in chloroform. $\mu \beta^{1.9}$ measured by EFISH at $1907 \mathrm{~nm}$ and $\beta^{1.9}$ measured by HRS at $1907 \mathrm{~nm}$.

\begin{tabular}{ccc} 
Compound & $\mu \beta^{1.9}{ }_{\text {EFISH }} / 10^{-48}$ & $\beta^{1.9}{ }_{\text {HRS }} / 10^{-30}$ \\
esu & esu \\
O1a & 26,000 & n.d. \\
O2a & 36,600 & n.d. \\
S1a & 103,000 & 3,320 \\
S1b & 86,300 & 2,600 \\
S1c & 87,500 & 4,880 \\
S2a & 115,000 & 2,680 \\
S3a & 37,000 & 3,010 \\
Se1a & 53,000 & 4,100 \\
Se1b & 67,000 & 2,370 \\
Se2a & 85,400 & 2,730 \\
Se2b & 78,500 & 6,540 \\
N1a & 99,200 & 3,070 \\
N2a & 94,100 & 2,960 \\
N3d & 28,000 & n.d. \\
\hline
\end{tabular}

\section{CONCLUSION}

In summary, a series of fifteen new TCF-based unsymmetrical polymethines has been synthesized. The introduction of bulky groups led to an increase of the thermal stability and a decrease of the effect of chromophore-chromophore interactions in films of pure dyes. The synthetic pathway enables the incorporation of selected heterocyclic donors having a direct influence on the electronic properties of the dyes. Solvatochromism experiments evidenced that the series of dyes tend to stabilize under a cyanine electronic structure in polar solvents. Finally, the combination of high intrinsic hyperpolarizability coupled with a large static dipolar moment results in excellent values of $\mu \beta$ for pyran-, thiopyran-, selenopyran- and benzoindoline-containing polymethines. From that point of view, these dyes are particularly promising for electro-optical modulation.

\section{ASSOCIATED CONTENT}

Additional spectroscopic details, thermogravimetric analysis, singlecrystal X-ray diffraction data, synthetic details and characterizations, including NMR spectra are provided. This material is available free of charge via the Internet at https://doi.org/10.1021/acs.chemmater.8b00960

\section{AUTHOR INFORMATION}

\section{Corresponding Author}

* S.P.: pascal@ cinam.univ-mrs.fr

* C.A.: chantal.andraud@ens-lyon.fr

*S.M.: seth.marder@ chemistry.gatech.edu

\section{ORCID}

Simon Pascal: 0000-0001-8387-494X

Yulia A. Getmanenko: 0000-0003-4099-8517

Guillaume Pilet: 0000-0002-0548-0651

Olivier Maury: 0000-0002-4639-643X

Isabelle Ledoux-Rak: 0000-0003-3192-6431

Stephen Barlow: 0000-0001-9059-9974

Seth R. Marder: 0000-0001-6921-2536

\section{Present Address}

${ }^{\perp}$ S.P. is currently at CINaM, Aix-Marseille Univ., UMR CNRS

7325, Campus de Luminy, 13288 Marseille Cedex 9, France

\section{Notes}

The authors declare no competing financial interest.

\section{ACKNOWLEDGMENT}

S.P. thanks the "Fondation de la Maison de la Chimie" for the attribution of a mobility grant (2012). Work at GT was supported by Air Force Office of Scientific Research through the COMAS MURI program (Agreement number FA9550-10-1-0558). H.M.N. acknowledges the fellowship from the Vietnam International Education Development "911 program".

\section{REFERENCES}

(1) Dalton, L. R.; Harper, A. W.; Ghosn, R.; Steier, W. H.; Ziari, M.; Fetterman, H.; Shi, Y.; Mustacich, R. V.; Jen, A. K. Y.; Shea, K. J., Synthesis and Processing of Improved Organic Second-Order Nonlinear Optical Materials for Applications in Photonics. Chem. Mater. 1995, 7 (6), 1060-1081.

(2) Dalton, L. R., Rational design of organic electro-optic materials. J. Phys.: Condens. Matter 2003, 15 (20), R897.

(3) Dalton, L. R.; Sullivan, P. A.; Bale, D. H., Electric Field Poled Organic Electro-optic Materials: State of the Art and Future Prospects. Chem. Rev. 2009, 110 (1), 25-55.

(4) Cheng, L. T.; Tam, W.; Stevenson, S. H.; Meredith, G. R.; Rikken, G.; Marder, S. R., Experimental investigations of organic molecular nonlinear optical polarizabilities. 1. Methods and results on benzene and stilbene derivatives. J. Phys. Chem. 1991, 95 (26), 1063110643.

(5) Robinson, B. H.; Dalton, L. R.; Harper, A. W.; Ren, A.; Wang, F.; Zhang, C.; Todorova, G.; Lee, M.; Aniszfeld, R.; Garner, S.; Chen, A.; Steier, W. H.; Houbrecht, S.; Persoons, A.; Ledoux, I.; Zyss, J.; Jen, A. K. Y., The molecular and supramolecular engineering of polymeric electrooptic materials. Chem. Phys. 1999, 245 (1-3), 35-50.

(6) Shi, Y.; Zhang, C.; Zhang, H.; Bechtel, J. H.; Dalton, L. R.; Robinson, B. H.; Steier, W. H., Low (Sub-1-Volt) Halfwave Voltage Polymeric Electro-optic Modulators Achieved by Controlling Chromophore Shape. Science 2000, 288 (5463), 119-122.

(7) Zhang, C.; Dalton, L. R.; Oh, M.-C.; Zhang, H.; Steier, W. H., Low V $\pi$ Electrooptic Modulators from CLD-1: Chromophore Design and Synthesis, Material Processing, and Characterization. Chem. Mater. 2001, 13 (9), 3043-3050.

(8) Cheng, Y.-J.; Luo, J.; Huang, S.; Zhou, X.; Shi, Z.; Kim, T.-D.; Bale, D. H.; Takahashi, S.; Yick, A.; Polishak, B. M.; Jang, S.-H.; Dalton, L. R.; Reid, P. J.; Steier, W. H.; Jen, A. K. Y., Donor-Acceptor Thiolated Polyenic Chromophores Exhibiting Large Optical Nonlinearity and Excellent Photostability. Chem. Mater. 2008, 20 (15), 5047-5054.

(9) Elder, D. L.; Haffner, C.; Heni, W.; Fedoryshyn, Y.; Garrett, K. E.; Johnson, L. E.; Campbell, R. A.; Avila, J. D.; Robinson, B. H.; Leuthold, J.; Dalton, L. R., Effect of Rigid Bridge-Protection Units, Quadrupolar Interactions, and Blending in Organic Electro-Optic Chromophores. Chem. Mater. 2017, 29 (15), 6457-6471.

(10) Haffner, C.; Heni, W.; Elder, D. L.; Fedoryshyn, Y.; Đorđević, N.; Chelladurai, D.; Koch, U.; Portner, K.; Burla, M.; Robinson, B.; Dalton, L. R.; Leuthold, J., Harnessing nonlinearities near material 
absorption resonances for reducing losses in plasmonic modulators. Opt Mater. Express 2017, 7 (7), 2168-2181.

(11) Kang, H.; Facchetti, A.; Zhu, P.; Jiang, H.; Yang, Y.; Cariati, E.; Righetto, S.; Ugo, R.; Zuccaccia, C.; Macchioni, A.; Stern, C. L.; Liu, Z.; Ho, S.-T.; Marks, T. J., Exceptional Molecular Hyperpolarizabilities in Twisted $\pi$-Electron System Chromophores. Angew. Chem. Int. Ed. 2005, 44 (48), 7922-7925.

(12) Kang, H.; Facchetti, A.; Jiang, H.; Cariati, E.; Righetto, S.; Ugo, R.; Zuccaccia, C.; Macchioni, A.; Stern, C. L.; Liu, Z.; Ho, S.-T.; Brown, E. C.; Ratner, M. A.; Marks, T. J., Ultralarge Hyperpolarizability Twisted $\pi$-Electron System Electro-Optic Chromophores: Synthesis, Solid-State and Solution-Phase Structural Characteristics, Electronic Structures, Linear and Nonlinear Optical Properties, and Computational Studies. J. Am. Chem. Soc. 2007, 129 (11), 3267-3286.

(13) He, G. S.; Zhu, J.; Baev, A.; Samoć, M.; Frattarelli, D. L.; Watanabe, N.; Facchetti, A.; Ågren, H.; Marks, T. J.; Prasad, P. N. Twisted $\pi$-System Chromophores for All-Optical Switching. J. Am. Chem. Soc. 2011, 133 (17), 6675-6680.

(14) Bouit, P.-A.; Wetzel, G.; Berginc, G.; Loiseaux, B.; Toupet, L.; Feneyrou, P.; Bretonnière, Y.; Kamada, K.; Maury, O.; Andraud, C., Near IR Nonlinear Absorbing Chromophores with Optical Limiting Properties at Telecommunication Wavelengths. Chem. Mater. 2007, 19 (22), 53255335 .

(15) Cabanetos, C.; Bentoumi, W.; Silvestre, V.; Blart, E.; Pellegrin, Y.; Montembault, V.; Barsella, A.; Dorkenoo, K.; Bretonnière, Y.; Andraud, C.; Mager, L.; Fontaine, L.; Odobel, F., New Cross-Linkable Polymers with Huisgen Reaction Incorporating High $\mu \beta$ Chromophores for Second-Order Nonlinear Optical Applications. Chem. Mater. 2012, 24 (6), 1143-1157.

(16) Bentoumi, W.; Mulatier, J.-C.; Bouit, P.-A.; Maury, O. Barsella, A.; Vola, J.-P.; Chastaing, E.; Divay, L.; Soyer, F.; Le Barny, P. Bretonnière, Y.; Andraud, C., Concise Multigram-Scale Synthesis of Push-Pull Tricyanofuran-Based Hemicyanines with Giant Second-Order Nonlinearity: An Alternative for Electro-optic Materials. Chem. Eur. J. 2014, 20 (29), 8909-8913.

(17) Hales, J. M.; Barlow, S.; Kim, H.; Mukhopadhyay, S.; Brédas, J.-L.; Perry, J. W.; Marder, S. R., Design of Organic Chromophores for All-Optical Signal Processing Applications. Chem. Mater. 2013, 26 (1), 549-560.

(18) Barlow, S.; Bredas, J. L.; Getmanenko, Y. A.; Gieseking, R. L.; Hales, J. M.; Kim, H.; Marder, S. R.; Perry, J. W.; Risko, C.; Zhang, Y. D., Polymethine materials with solid-state third-order optical susceptibilities suitable for all-optical signal-processing applications. Mater. Horiz. 2014, 1 (6), 577-581.

(19) Marder, S. R.; Gorman, C. B.; Tiemann, B. G.; Perry, J. W. Bourhill, G.; Mansour, K., Relation Between Bond-Length Alternation and Second Electronic Hyperpolarizability of Conjugated Organic Molecules. Science 1993, 261 (5118), 186-189.

(20) Gorman, C. B.; Marder, S. R., An investigation of the interrelationships between linear and nonlinear polarizabilities and bondlength alternation in conjugated organic molecules. Proc. Natl. Acad. Sci. U.S.A. 1993, 90 (23), 11297-11301.

(21) Marder, S. R.; Cheng, L.-T.; Tiemann, B. G.; Friedli, A. C.; Blanchard-Desce, M.; Perry, J. W.; Skindhøj, J., Large First Hyperpolarizabilities in Push-Pull Polyenes by Tuning of the Bond Length Alternation and Aromaticity. Science 1994, 263 (5146), 511-514.

(22) Ahlheim, M.; Barzoukas, M.; Bedworth, P. V.; BlanchardDesce, M.; Fort, A.; Hu, Z.-Y.; Marder, S. R.; Perry, J. W.; Runser, C. Staehelin, M.; Zysset, B., Chromophores with Strong Heterocyclic Acceptors: A Poled Polymer with a Large Electro-Optic Coefficient. Science 1996, 271 (5247), 335-337.

(23) Tolbert, L. M.; Zhao, X., Beyond the Cyanine Limit: Peierls Distortion and Symmetry Collapse in a Polymethine Dye. J. Am. Chem Soc. 1997, 119 (14), 3253-3258.

(24) Pascal, S.; Haefele, A.; Monnereau, C.; Charaf-Eddin, A. Jacquemin, D.; Le Guennic, B.; Andraud, C.; Maury, O., Expanding the
Polymethine Paradigm: Evidence for the Contribution of a Bis-Dipolar Electronic Structure. J. Phys. Chem. A 2014, 118 (23), 4038-4047.

(25) Brooker, L. G. S.; Sprague, R. H., Color and Constitution. IV.1 The Absorption of Phenol Blue. J. Am. Chem. Soc. 1941, 63 (11), 3214 3215 .

(26) Brooker, L. G. S.; Keyes, G. H.; Williams, W. W., Color and Constitution. V.1 The Absorption of Unsymmetrical Cyanines. Resonance as a Basis for a Classification of Dyes. J. Am. Chem. Soc. 1942, 64 (2), 199-210.

(27) Brooker, L. G. S.; Keyes, G. H.; Sprague, R. H.; Van Dyke, R. H.; Van Lare, E.; Van Zandt, G.; White, F. L., Studies in the Cyanine Dye Series. XI.1 The Merocyanines. J. Am. Chem. Soc. 1951, 73 (11), 53265332.

(28) Brooker, L. G. S.; Keyes, G. H.; Sprague, R. H.; Van Dyke, R. H.; Van Lare, E.; Van Zandt, G.; White, F. L.; Cressman, H. W. J.; Dent, S. G., Color and Constitution. X.1 Absorption of the Merocyanines2. J. Am. Chem. Soc. 1951, 73 (11), 5332-5350.

(29) Brooker, L. G. S.; Craig, A. C.; Heseltine, D. W.; Jenkins, P. W.; Lincoln, L. L., Color and Constitution. XIII.1 Merocyanines as Solvent Property Indicators2. J. Am. Chem. Soc. 1965, 87 (11), 24432450 .

(30) Dähne, S., Color and Constitution: One Hundred Years of Research. Science 1978, 199 (4334), 1163-1167.

(31) Dähne, S.; Hoffmann, K., Colour and constitution: linear free energy relationships and/or polymethinic colour rules? J. Mol. Struct. 1990, 219, 403-409.

(32) Dähne, S., Der ideale Polymethinzustand. Chimia 1991, 45 (10), 288-296.

(33) Marder, S. R.; Perry, J. W.; Tiemann, B. G.; Gorman, C. B.; Gilmour, S.; Biddle, S. L.; Bourhill, G., Direct observation of reduced bond-length alternation in donor/acceptor polyenes. J. Am. Chem. Soc. 1993, 115 (6), 2524-2526.

(34) Marder, S. R.; Gorman, C. B.; Tiemann, B. G.; Cheng, L. T., Stronger acceptors can diminish nonlinear optical response in simple donor-acceptor polyenes. J. Am. Chem. Soc. 1993, 115 (7), 3006-3007.

(35) Würthner, F.; Wortmann, R.; Matschiner, R.; Lukaszuk, K.; Meerholz, K.; De Nardin, Y.; Bittner, R.; Bräuchle, C.; Sens, R., Merocyanine Dyes in the Cyanine Limit: A New Class of Chromophores for Photorefractive Materials. Angew. Chem. Int. Ed. 1997, 36 (24), 2765 2768.

(36) Würthner, F.; Archetti, G.; Schmidt, R.; Kuball, H.-G., Solvent Effect on Color, Band Shape, and Charge-Density Distribution for Merocyanine Dyes Close to the Cyanine Limit. Angew. Chem. Int. Ed. 2008, 47 (24), 4529-4532.

(37) For the ionic polymethines the polyene-like spectra are favored in higher polarity solvents, in contrast to what is seen here. However, if such spectra of ionic species are indeed attributable to "symmetry-broken" polyene-like structures then the positive charge would be more localized in the polyene form and so better stabilized by more polar solvents, whereas in the present case, a cyanine-like form would exhibit a larger dipole than the polyene-like and so be favored by polar solvent.

(38) Lepkowicz, R. S.; Przhonska, O. V.; Hales, J. M.; Fu, J.; Hagan, D. J.; Van Stryland, E. W.; Bondar, M. V.; Slominsky, Y. L.; Kachkovski, A. D., Nature of the electronic transitions in thiacarbocyanines with a long polymethine chain. Chem. Phys. 2004, 305 (1-3), 259-270.

(39) Kachkovski, O. D.; Tolmachov, O. I.; Slominskii, Y. L.; Kudinova, M. O.; Derevyanko, N. O.; Zhukova, O. O., Electronic properties of polymethine systems 7: soliton symmetry breaking and spectral features of dyes with a long polymethine chain. Dyes Pigm. 2005, 64 (3), 207-216.

(40) Terenziani, F.; Przhonska, O. V.; Webster, S.; Padilha, L. A.; Slominsky, Y. L.; Davydenko, I. G.; Gerasov, A. O.; Kovtun, Y. P.; Shandura, M. P.; Kachkovski, A. D.; Hagan, D. J.; Van Stryland, E. W.; Painelli, A., Essential-State Model for Polymethine Dyes: Symmetry Breaking and Optical Spectra. J. Phys. Chem. Lett. 2010, 1 (12), 18001804. 
(41) Vasyluk, S. V.; Viniychuk, O. O.; Poronik, Y. M.; Kovtun, Y. P.; Shandura, M. P.; Yashchuk, V. M.; Kachkovsky, O. D., Breaking of symmetrical charge distribution in xanthylocyanine chromophores detecting by their absorption spectra. J. Mol. Struct. 2011, 990 (1), 6-13.

(42) Przhonska, O. V.; Hu, H.; Webster, S.; Bricks, J. L.; Viniychuk, A. A.; Kachkovski, A. D.; Slominsky, Y. L., Electronic transitions in a series of 2-azaazulene polymethine dyes with different $\pi$-conjugation lengths. Chem. Phys. 2013, 411, 17-25.

(43) Detty, M. R.; Hassett, J. W.; Murray, B. J.; Reynolds, G. A., $\Delta 4,4$ ' -4-chalcogenapyranyl-4h-chalcogenapyrans. Tetrahedron 1985, 41 (21), 4853-4859

(44) Masunov, A. E.; Anderson, D.; Freidzon, A. Y.; Bagaturyants, A. A., Symmetry-Breaking in Cationic Polymethine Dyes: Part 2. Shape of Electronic Absorption Bands Explained by the Thermal Fluctuations of the Solvent Reaction Field. J. Phys. Chem. A 2015, 119 (26), 6807-6815.

(45) Scarpaci, A.; Nantalaksakul, A.; Hales, J. M.; Matichak, J. D.; Barlow, S.; Rumi, M.; Perry, J. W.; Marder, S. R., Effects of Dendronization on the Linear and Third-Order Nonlinear Optical Properties of Bis(thiopyrylium) Polymethine Dyes in Solution and the Solid State. Chem. Mater. 2012, 24 (9), 1606-1618.

(46) Davydenko, I.; Barlow, S.; Sharma, R.; Benis, S.; Simon, J.; Allen, T. G.; Cooper, M. W.; Khrustalev, V.; Jucov, E. V.; Castañeda, R.; Ordonez, C.; Li, Z. a.; Chi, S.-H.; Jang, S.-H.; Parker, T. C.; Timofeeva, T. V.; Perry, J. W.; Jen, A. K. Y.; Hagan, D. J.; Van Stryland, E. W.; Marder, S. R., Facile Incorporation of $\mathrm{Pd}(\mathrm{PPh} 3) 2 \mathrm{Hal}$ Substituents into Polymethines, Merocyanines, and Perylene Diimides as a Means of Suppressing Intermolecular Interactions. J. Am. Chem. Soc. 2016, 138 (32), 10112-10115.

(47) The trend in oxidation potentials may arise from an interplay of the inherent electron-richness of the heterocycles, which decreases from $\mathrm{O}$ to $\mathrm{Se}$, and the extent to which this electron-richness reduced by $\pi$ donation to the acceptor.

(48) Oudar, J. L.; Chemla, D. S., Hyperpolarizabilities of the nitroanilines and their relations to the excited state dipole moment. $J$. Chem. Phys. 1977, 66 (6), 2664-2668.

(49) Ledoux, I.; Zyss, J., Influence of the molecular environment in solution measurements of the Second-order optical susceptibility for urea and derivatives. Chem. Phys. 1982, 73 (1), 203-213.

(50) Maker, P. D., Spectral Broadening of Elastic Second-Harmonic Light Scattering in Liquids. Phys. Rev. A 1970, 1 (3), 923-951.

(51) Terhune, R. W.; Maker, P. D.; Savage, C. M., Measurements of Nonlinear Light Scattering. Phys. Rev. Lett. 1965, 14 (17), 681-684.

(52) Brasselet, S.; Zyss, J., Multipolar molecules and multipolar fields: probing and controlling the tensorial nature of nonlinear molecular media. J. Opt. Soc. Am. B 1998, 15 (1), 257-288. 